\title{
Correction to: New Trends in Removing Heavy Metals from Industrial Wastewater Through Microbes
}

Mohammad Haris, Adnan Shakeel, Touseef Hussain, Gufran Ahmad, Moh. Sajid Ansari, and Abrar Ahmad Khan

\section{Correction to: \\ Chapter 9 in: M. P. Shah (ed.), Removal of Emerging \\ Contaminants Through Microbial Processes, https://doi.org/10.1007/978-981-15-5901-3_9}

Owing to an oversight, this chapter was initially published with incorrect authorship. One of the author's names, Moh. Sajid Ansari, was inadvertently removed during the production process. The chapter has now been amended with the correct authorship. 